\title{
Metastatic adenocarcinoma in a young male, 12 years after treatment of primary non seminomatous germ cell tumor
}

\author{
Pragnya Coca, \\ Sadashivudu Gundeti, \\ Shantiveer Uppin ${ }^{1}$, \\ Raghunadharao Digumarti \\ Departments of Medical Oncology \\ and ${ }^{1}$ Pathology, Nizam's Institute \\ of Medical Sciences, Punjagutta, \\ Hyderabad, Andhra Pradesh, India \\ Address for correspondence: \\ Dr. Pragnya Coca, \\ Department of Medical Oncology, \\ Nizam's Institute of Medical \\ Sciences, Punjagutta, \\ Hyderabad, Andhra Pradesh, India. \\ E-mail: pragnya.11@gmail.com
}

\section{A B S T R A C T}

A man aged 32 years presented with metastatic adenocarcinomatous deposits, 12 years after his initial diagnosis and treatment of immature teratoma of the testis. $\mathrm{He}$ was treated for his metastasis with local radiotherapy, failing which he underwent excision of the tumor and palliative chemotherapy. This case is presented for its rarity of occurrence, unique presenting features and difficulty in management.

Key words: Adenocarcinoma, immature teratoma, transformation

\section{INTRODUCTION}

Although germ cell tumors (GCTs) account for only $2 \%$ of all human malignancies, they are the most common tumors diagnosed in men aged 15-35 years. Being chemoresponsive, more than $90 \%$ of newly diagnosed patients are cured with standard chemotherapy.

Transformation of the teratomatous component in a GCT to a histology that is identical to a somatic malignancy is a rare occurrence seen in 3-6\% patients with GCT with teratomatous differentiation. Examples of transformed cell types include rhabdomyosarcoma (RMS), primitive neuroectodermal tumor (PNET), enteric adenocarcinoma, and leukemia. This transformation is more commonly seen in mediastinal nonseminomatous germ cell tumors (NSGCT) than from gonadal or retroperitoneal primary tumors. The identification of $\mathrm{i}(12 \mathrm{p})$ or excess $12 \mathrm{p}$ chromosome copy number in these tumors establishes the clonal-origin of these malignant cells.

\begin{tabular}{|l|l|}
\hline \multicolumn{2}{|c|}{ Access this article online } \\
\hline Quick Response Code: & Website: \\
\hline & www.jmpo.org \\
\hline
\end{tabular}

Surgical resection has been the mainstay of therapy when the transformation is localized to a single site. Chemotherapy has a role in selected cases of metastatic transformation and treatment is determined by the cell type.

\section{CASE REPORT}

This man first presented to us at the age of 18 years with complaints of a painless left testicular swelling and a paramedian abdominal mass extending from the left side of umbilicus to left iliac fossa. Investigations revealed alphafetoprotein (AFP) $455 \mathrm{ng} / \mathrm{ml}$ and beta human chorionic gonadotropin (B-HCG) $575 \mathrm{mIU} / \mathrm{ml}$. A high inguinal orchidectomy specimen showed features of embryonic carcinoma with immature teratoma [Figure 1]. He received three cycles of chemotherapy with Etoposide, Cisplatin and Ifosphamide. Chemotherapy was followed by retroperitoneal lymph nodal dissection which showed pathological features of teratocarcinoma. Postoperatively, abdominal sonogram showed no evidence of residual disease. He received one more cycle of chemotherapy, which he tolerated poorly. Tumor markers became undetectable. Hence, further chemotherapy was stopped. He was regularly observed for a period of 5 years, after which he was lost to follow-up.

He presented to us, 12 years after his first presentation, at 
the age of 30 years, with left-sided chest pain of 2 months duration. He was evaluated with a bone scan which showed diffuse, but avid, uptake in left $10^{\text {th }}$ rib posteriorly, and in adjacent $10^{\text {th }}$ dorsal vertebrae, suspicious of metastasis. Tumor markers were within normal limits. Magnetic resonance imaging (MRI) of the dorso-lumbar (DL) spine [Figures 2 and 3] showed metastatic involvement of the D10 vertebral body with secondary deposits in left paravertebral region at D10 level extending into D10-D11 spinal canal and causing erosion of left $10^{\text {th }}$ rib. Computed tomography (CT) guided biopsy [Figure 4] from the D10 lesion showed adenocarcinoma - metastasis in a known case of NSGCT of testis. He received local radiation therapy (RT) to the dorsal spine at 40Gy in 16 fractions over a 10 day period.

Three months after RT, on revaluation, an MRI DL spine showed a persistent paraspinal mass with some regression of the intraspinal component. Positron emission

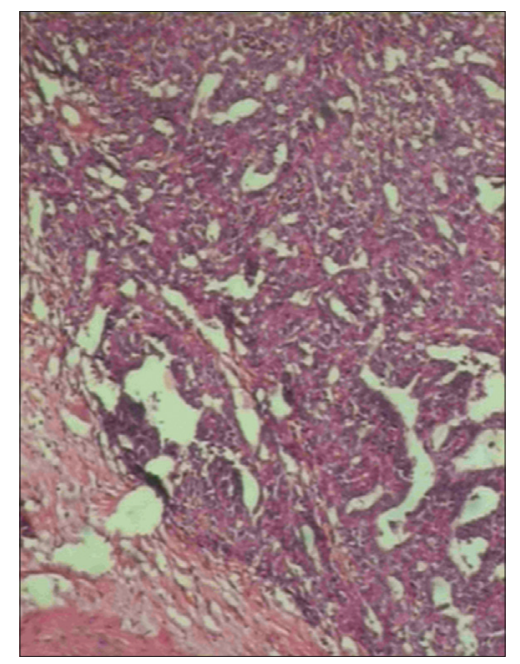

Figure 1: Photomicrograph of immature teratoma with embryonal carcinoma: $\mathrm{H}$ and $\mathrm{E}, \times 100$

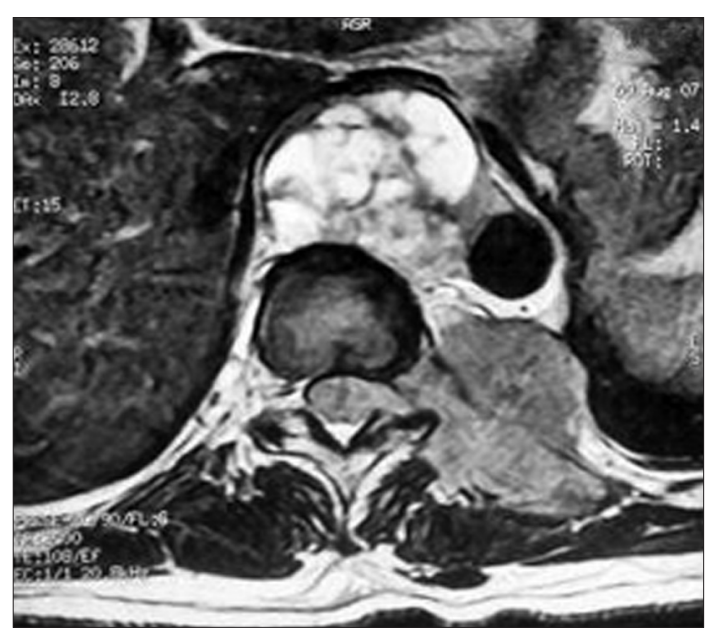

Figure 3: MRI DL spine (coronal section) showing tumor mass extending along the left $10^{\text {th }}$ rib at the costo-vertebral angle tomography (PET)-CT scan showed a metabolically active left $10^{\text {th }}$ rib and necrotic paravertebral nodes. As, he was asymptomatic, no further intervention was undertaken.

A year later, he returned with recurrent symptoms and tumor progression, for which he received another course of local RT.

One year after his second course of RT, he presented with reappearance of radicular pain along the left lower costal margin, hesitancy, weakness and numbness of both lower limbs. On re-evaluation, CT scan showed increase in the extent of involvement of left $10^{\text {th }}$ rib and paravertebral mass. He underwent an immediate decompression of the tumor with D10 to D11 laminectomy, excision of the extradural mass and en bloc excision of $\mathrm{Lt} 9^{\text {th }} / 10^{\text {th }} / 11^{\text {th }}$ ribs.

Postoperatively, the patient was started on palliative chemotherapy with Paclitaxel and Carboplatin. Response

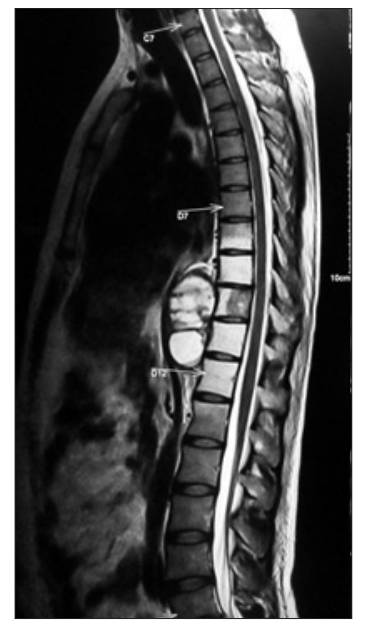

Figure 2: MRI DL spine (longitudinal section) showing large, heterogeneous enhancing mass extending from D9 to D12 with altered signal intensity of D10 vertebrae

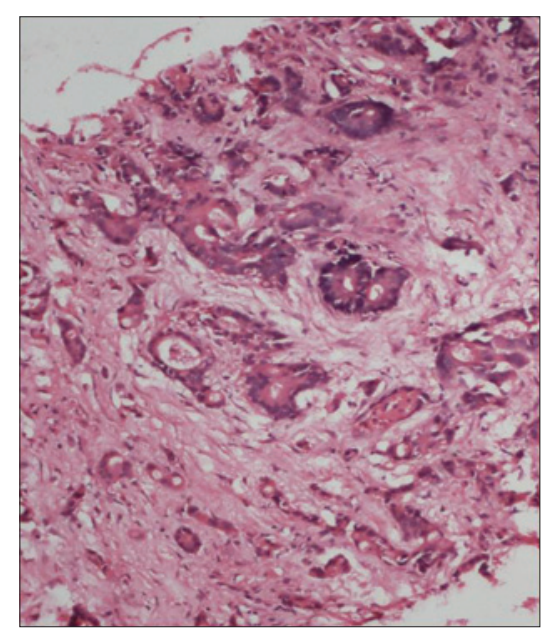

Figure 4: Adenocarcinoma deposits in D10 vertebral body biopsy: $\mathrm{H}$ and $\mathrm{E}, \times 100$ 
evaluation after four cycles showed evidence of progressive disease. He further underwent D10 corpectomy with excision of the tumor and spinal stabilization with cage reconstruction of D10 vertebra. His was changed to a 5-Flurouracil (5-FU) based chemotherapy regimen.

\section{DISCUSSION}

The earliest report of transformation to a somatic malignancy in teratomas was published by Ulbright et al. ${ }^{[1]}$ in 11 male patients with GCT. The authors proposed that these malignant elements arose within teratomatous foci when cisplatin therapy "unmasks" the non-germ cell malignant elements by destroying the more chemosensitive germ cell types.

In a case series by Mozter et al. ${ }^{[2]} 46$ patients with transformed teratomas were studied. Sarcoma was the most frequent histology identified in 29 patients (63\%). Adenocarcinoma and PNET were the other most common histologies.

In a study by Donadio et al., ${ }^{[3]}$ patients with transformed teratomas, from 1988 to 2002, were identified from the review of the GCT database at Memorial SloanKettering Cancer Center. A total of 10 patients with measurable disease were identified. Among these patients, only two had developed adenocarcinoma as the transformed malignant histology. Amongst all transformed histologies, only patients with adenocarcinoma developed their disease 20 or more years after their initial GCT diagnosis. These two patients went on to receive 5-FU based chemotherapy which was instrumental in achieving only a partial response, and response duration of only 2 years. The presence of transformed teratomatous components at metastatic sites implied a poor prognosis, with a median survival time of only 28 months.

To the best of our knowledge, there is no case report from India of malignant transformation of teratoma after a long latent period of 12 years. Total surgical excision of the lesion is the treatment of choice for localized disease, especially for carcinoma/adenocarcinoma component as part of malignant transformation. The role of chemotherapy and radiotherapy is limited. In this case, local control could not be achieved due to the presence of an intraspinal component. The management of this patient was thus a therapeutic challenge.

\section{CONCLUSION}

Teratoma with malignant transformation is a rare occurrence. A long latent interval between the primary diagnosis and secondary metastatic presentation is consistent with adenocarcinoma.

\section{ACKNOWLEDGMENT}

Dr. B. H. Srinivas, Senior Resident, Department of Pathology, Nizam's Institute of Medical Sciences, Hyderabad, is gratefully acknowledged.

\section{REFERENCES}

1. Ulbright TM, Loehrer PJ, Roth LM, Einhorn LH, Williams SD, Clark SA. The development of non-germ cell malignancies within germ cell tumors: A clinicopathologic study of 11 cases. Cancer 1984;54:1824-33.

2. Motzer RJ, Amsterdam A, Prieto V, Sheinfeld J, Murty VV, Mazumdar $\mathrm{M}$, et al. Teratoma with malignant transformation: Diverse malignant histologies arising in men with germ cell tumors. J Urol 1998;159:133-8.

3. Donadio AC, Motzer RJ, Bajorin DF, Kantoff PW, Sheinfeld J, Houldsworth J, et al. Chemotherapy for teratoma with malignant transformation. J Clin Oncol 2003; 21:4285-91.

How to cite this article: Coca P, Gundeti S, Uppin S, Digumarti R. Metastatic adenocarcinoma in a young male, 12 years after treatment of primary non seminomatous germ cell tumor. Indian $\mathrm{J}$ Med Paediatr Oncol 2011;32:115-7.

Source of Support: Nil, Conflict of Interest: None declared.

Announcement

Android App

A free application to browse and search the journal's content is now available for Android based mobiles and devices.. The application provides "Table of Contents" of the latest issues, which are stored on the device for future offline browsing. Internet connection is required to access the back issues and search facility. The application is compatible with all the versions of Android. The application can be downloaded from https://market.android.com/details?id=comm.app.medknow. For suggestions and comments do write back to us. 